\title{
Eski Mezopotamya Mitolojisinde İnsanın Yaratılışı
}

* Sorumlu Yazar / Corresponding Author: Murat Çayır Ankara Üniversitesi Dil ve Tarih - Coğrafya Fakültesi Sümeroloji Anabilim Dalı 06100 Sihhiye, Ankara / TÜRKIYE

Murat Çayır ${ }^{1^{*}} \odot$ E-posta: mcayir@ankara.edu.tr

'Dr. Öğr. Üyesi, Ankara Üniversitesi, Dil ve Tarih - Coğrafya Fakültesi, Sümeroloji Anabilim Dalı, Ankara / TÜRKIYE

Alındı/Received: 4 Şubat / February 2020 Düzeltildi/Revised: 9 Mart / March 2020

Kabul/Accepted: 9 Mart / March 2020 Yayımlandı/Published: 29 Haziran / June 2020

\section{$\ddot{O} z$}

Eski Yunan'da “geçmişte söylenenlerin tekrar edilmesi” gibi bir anlama gelen Mitoloji, belirli bir din, inanış veya kültürdeki, insanlık ile evrenin yaratılış ve doğasını, geleneklere özgü inanç ve uygulamaların sebebini açıklamaya yönelik söylencelerin tümünü tanımlamak için kullanılmıştır. M.Ö. 3200’lerde Güney Mezopotamya'da büyük bir kültür ve medeniyet inşa etmiş Sumerler'in bulduğu çivi yazısı, Mezopotamya ve Anadolu'da çeşitli kavimlerce uzun yıllar boyunca kullanılmış ve insanlık tarihine çeşitli konularda binlerce yazılı belge kalmıştır. Bunlar arasında önemli bir grubu oluşturan mitolojik metinlerde yer alan insanın yaratıllı̧ hikâyesi oldukça dikkat çekicidir. Bu çalışmada bu konuyla ilgili çivi yazılı kaynaklarda geçen hikâyeleri sunmaya çalışacağız.

Anahtar Sözcükler: Eski Mezopotamya, mitoloji, insanın yaratılışı

\section{Giriş}

İnsanllk tarihinin araştırlılmasında ve yorumlanmasında en önemli kaynaklar tartıșmasız yazılı belgelerdir. 16. yüzyllda Batllı gezginler, kutsal kitaplarda belirtilen yerleri keşfetmek için Mezopotamya'ya seyahatlerde bulunmuşlar ve burada özellikle yerli halk sayesinde elde ettikleri çivi yazilı belgeleri beraberlerinde Avrupa'ya götürmüşlerdir. 19. yüzyllın başlarında ise bilim adamları tarafindan çivi yazılı belgeler üzerinde yapılan çalş̧malar, ilk uygarlıkların ortaya çıktığı Mezopotamya ve Anadolu'daki medeniyetler hakkında bilgi sahibi olmamızı sağlamıştır.

Civi yazılı kaynaklar üzerindeki çalıșmalardan önce, İlkçağ tarihi konusundaki bilgilerimiz başta Tevrat olmak üzere kutsal kitaplarda ve antik dönem yazarlarının eserlerinde yazılanlara dayanıyordu ve bu çağa ait çoğu bilginin kaynağının Eski Yunan olduğu düşünülüyordu. $1900^{\prime} l u ̈$ ylllardan sonra bu görüş̧ değişmiş, Batı kültürünün Eski Önasya’dan etkilendiği ortaya çıkmıştır (Günbattı, 2017). Asuroloji alanında önemli bir araştırmacı olan Fransız Jean

\section{The Creation of Humans in Ancient Mesopotamian Mythology}

Abstract

Mythology, which means something as the "repetition of what has been said in the past", was used in ancient Greece to describe all the rumors in a particular religion, belief or culture to explain the creation and nature of bumanity and the universe, the beliefs and the practices specific to tradition. The cuneiform found by Sumerians in the 3200 B.C. who built a great culture and civilization in Southern Mesopotamia had been used by various tribes in Mesopotamia and Anatolia for many years and thousands of written documents have remained in human history on various subjects. The story of the creation of humans, which takes place in mythological texts that constitute an important group among these, is quite remarkable. In this study, we will try to present the stories mentioned in cuneiform sources on this subject.

Key Words: Ancient mesopotamia, mythology, creation of bumans

Bottéro, "Helenistler arasında en tutucuları bile açıkça söylemeseler de Eski Yunan'ın hem kültür hem de başka alanlarda Doğu'dan, yani daha en başından o saygin, o muazzam Mezopotamya'dan ne derece etkilendiğini bugün arttk inkâr edemiyor" demektedir (Bottéro, 2003, s. 45).

M.Ö. 3200'lerde Güney Mezopotamya'da büyük bir kültür ve medeniyet inșa etmiş Sumerler'in keşfettiği çivi yazısı, Mezopotamya ve Anadolu'da çeşitli kavimlerce uzun yıllar boyunca kullanılmıştır. Bu yazı, başta Sumerce olmak üzere, Akadca ve onun iki ana lehçesi Asurca ve Babilce ile Hititçe gibi dillere uygulanmıştrr. Bu sayede Eski Mezopotamya ve Eski Anadolu kültürleri hakkında önemli bilgiler elde etme şansımız olmuştur.

Çalışmamızda, oldukça geniş̧ olan Eski Mezopotamya mitoloji külliyatında önemli bir yere sahip insanın yaratılışı konusunu, çivi yazılı kaynaklar ışığında sunmaya çalışacağız. Bu konuda, Sumeroloji ve Asuroloji alanında önde gelen araştırmacılardan Jean Bottéro ve Samuel Noah Kramer'in "Mezopotamya 
Mitolojisi" adlı kitabını (Bottéro ve Kramer, 2017) kılavuz eser olarak kullandığımızı belirtmek isteriz.

\section{Mitoloji nedir?}

Mitoloji, Yunanca muthos "anlatılan ya da duyulan söz" ve logos "konuşma”" kelimeleriyle oluşmuş, Eski Yunan'da "geçmişte anlatılanların konuşulması, tekrar edilmesi" gibi bir anlama gelmektedir.

Mitler, arkaik toplumlarda doğaüstü varlıkların yaptıklarının hikâyelerini oluşturur. Bunlar mutlak gerçek ve kutsal (doğaüstü varlıklar tarafindan yapıldığ1 için) sayılır. Mitler çoğunlukla yaratılışla ilgilidir. Bir şeyin nasıl varlık bulduğunu, bir davranışın, bir kurumun, bir çalışma biçiminin nasıl olduğunu anlatırlar. Kısacası mitler, dünyanın, insanın ve yaşamın doğaüstü bir kökeni ve tarihi olduğunu; bu tarihin anlaml, değerli ve ibret alınacak olaylarla dolu olduğunu ortaya koyar (Bonnefoy, 2000).

Eski Yunan mitolojisinin de temelini oluşturan Eski Mezopotamya'da yer alan mitlerin hemen hepsi o dönemin inanç sistemi ile ilgilidir. Fakat bunların yer aldığı metinlerde anlatılanlar, hiçbir zaman inançla ilgili duyguları direkt ifade etmek veya kurallar koymak amacında olmamıslardır. Bu hikâyeler duyguları değil, olayları anlatmak için yazılmışlardır. Aslında her biri önemli edebî eserdir.

Mezopotamya mitolojisinde insanın yaratılışının anlatıldığ1 mit türüne antropogoni adı verilmektedir. Aslında bu tür, teogoni (tanrıların yaratılışı) ve kozmogoni (evrenin yaratılışı) mitleriyle ayrılmaz bir bütün halindedir. Mezopotamya'da tam bir antropogoni özelliği taşıyan iki metin bulunmaktadır. Bunlar Enki ve Ninmah miti ve Atrahasis/Ulu Bilge Şiiri'dir. Bunları incelemeye başlamadan önce yukarıda belirttiğimiz teogoni, kozmogoni ve antropogoni unsurları içeren bazı metinlere değinmek yerinde olacaktır.

1. Sumerceve Akadca olmak üzereiki dilde düzenlenmiş 52 satırdan oluşan bir mite ait en eski nüsha, Asur kralı I. Tiglatpileser'in (M.Ö. 1115-1077) ${ }^{1}$ kitaplığ1 adı verilen bir kaynakta yer almaktadır (Weidner, 1952/1953). Bu mitin ve inceleyeceğimiz diğer metinlerin tercümelerinin tamamını bu çalışmada vermek mümkün olamayacağından -çünkü bazıları yüzlerce hatta binlerce satır olarak yazılmıs- önemli bulduğumuz satırların tercümelerini vereceğiz.

Mitin ilk satırlanndaki "Gök aymldiğmda Yer'den, - o zamana kadar sağlamca birdiler- Ana tanriçalar ortaya

\footnotetext{
${ }^{1}$ Bazı Akadça isimler batılı kaynaklara, yazıldığı dile uygun bir hale getirilerek geçmiştir. Akadças1-Tukulti-apil-ešerra olan Tiglatpileser de bunlardan birisidir (Bazı örnekler: Nabukadnezar-Nabukudurri-usur; Aššurbanipal-Ašşur-bani-apli; Sargon-Šarru-kēn).
}

cıktıklarmda, yer kurulduğunda ve yerine koyulduğunda" ifadelerinden bu mitin evrenin yaratılışıyla (kozmogoni) ilgili unsurlar da içerdiğini görüyoruz. Sonraki satırlarda tanrıların insanları yaratma amaçlarının ne olduğunu okuyoruz:

"Tanrlar evrenin programmiyaptıklarmda sulama sistemini hazırlamak için Dicle ve Furat'in akıșin sağladıklarnda An, Enlil, Ninmah, büyük tanrlar ve de öteki büyüle tanrlar: Anunnallar yü̈ksek kerevetlerine yerlestiler ve görüsüp tartıștılar.

Evrenin programun coktan belirlemislerdi. Dicle ve Furat'in sularyla oluşan sulama sistemini hažrlamak için Enlil sordu onlara: 'Ya şimdi ne yapacağrz? Ne imal edeceğiz simdi? Ey büyük tanrlar, Anunnalar ne yapacağız, simdi? Ne yaratacağı??

$V e$ orada bulunan büyüle tannlar, kaderleri dağgtan Anunnna'lar tek bir ağrzdan cevap verdi Enlil'e: 'Duranki'nin (Nippur şebri) et imalathanesinde iki tane tanrisal Alla kurban edeceğir: Onlarm kanndan da insanlar dünyaya getireceğiz! Tanrlar için yapulacak angarya onlarm angaryasi olacak. Tarlalarn sinurlarm belirleyecekler, bir kerede ve temelli sulama sistemini kuracaklar...... Ülkenin zenginliğini artıracaklar, tanrlarm șenliklerini laynkıyla kutlayacaklar, büyük eve taze su boșaltacaklar yü̈ksek kerevetin saygzdeger yerine! Onlara Ullegarra ve Annegarra denilecek, ülkenin bereketi için siğrrlar, koyunlar, (diğer) hayvanlar, balıklar ve kuşlar çoğaltacaklar.' "

Metnin son bölümünde ise tanrıların bu kararlarının kesin olduğu ve tüm tanrılar tarafindan onaylandığı belirtilmiştir.

Mitin anlattığ yerine getirmesi gereken sorumlulukları üstlenmeleri için yaratılmasıdır. İnsanlar, Mezopotamya toprakları için önemli olan sulama sistemini kuracaklar ve böylece tarım gelişecek, hayvancılığ ve balıkçılığı geliştirip ülkenin refahını sağlayacaklar ve aynı zamanda bunu tanrılarıyla paylaşacaklardır. Bu mitin bir başka önemli yanı ilk yaratılan insanlara Ullegarra ve Annegarra adlarının verilmesidir. Bu isimlere etimolojik olarak bakacak olursak hem Sumerce hem de Akadca dil unsurlar1 içerdiğini görürüz. Akadca ullû "zaman olarak uzak, eski" annû "şimdi (zaman olarak yeni)" kelimeleri, Sumerce gar "koymak, yerleştirmek, tesis etmek, kurmak" filitile birlikte belki de "hayata önce ve sonra gelen" anlamında kullanılmıştır.

2. Yedi tablet ve yüzlerce satırdan oluşan ve büyük bir bölümünde tanrı Marduk'un yüceltilmesi konu edilen Babil yaratilış destanı Enuma Elis'in birinci tabletinde evrenin ve tanriların yaratılışı anlatılmaktadır. Destanın altıncı tabletinin ilk bölümünde ise insanın yaratılışı konu edilmiştir:

"Marduk duyunca dediklerini tanrlarm, yüreği hemen onu harikalar yaratmaya itti! Ağðın açtı ve söyledi Ea'ya açtı ona yüreğinde olgunlaştırdiğ amacm: 'Kan yoğunlaştıracağım, 
bir iskelet olusturacağm ve böylece bir Lulu (insan prototipi) yaratacağm. Adr 'insan' olacak!! Bu Lulu, bu insan onu yaratacağım ki tanrlarm angaryalar yüklensin onun sirtma onlar rabat etsin diye'......... Kingu tek bașina tezgâbladr sarpısmay isyana kusskurtt Tiamat' ve tertipledi savası! Sike sike bağladılar onu ve Ea'nin önünde tuttular: Sonra cezasin vermek için kanm akuttular ve onun kanuyla yarattı Ea insanliğ, tanrlarm angaryalarm insanliğa yükledi ve tanrları kurtardl."

3. M.Ö. 2. bin yılın başına ait Sumerce yazılmış kısa bir şiir hem kozmogoni hem de antropogoni unsurlar1 içermektedir. Metnin ilk satırlarında tanrı Enlil'in yaratılışın sorumlusu olduğundan bahsedilir:

"Aslinda Efendi (Enlil) ortaya çıkardı ne varsa! Bütün kaderleri sonsuz kadar bağlayan Efendi, ülkenin ilk ürünlerini topraktan çekip çıkarmadan önce Gök'ü Yer'den ayırdı! Yeri Gök'ten ayurd!?'

Metnin sonraki satırlarında insanların angaryaları yaparken kullanacakları gereçlerden tarla çapasının icadı şu sözlerle anlatılır:

"Et imalathanesinde dünyaya getirmek için başın (insan soyunun) Durankiden (Nippur) bir kazlk getirdi. Tarla sapasım yaptı ondan. Hemen ertesi gün de angaryayn getirdi. Böylece (gelecek insanlarn kaderini tâyin etti."

Şiirin son satırlarında insanın yaratılışı ve tarla çapasının insanlara aktarılışı yazılmıştır:

"Efendi onlarn kaderini tayin etti. Yesilliketen yapulma bir taç(?) koyup ürerine et imalathanesine götürdü ve (insan soyunun başın kaliba koyarken yararlandı ondan. Bundan sonra, onun önünde çoğaldr insanlar, aşağzda! Enlil hep göz. kulak oluyordu kara kafalilara. Saray erkanm olusturan Anunnnalar inançla kapattılar ağızlarm elleriyle övdüler Enlil'i ve aktardılar tarla çapasm kara kafallara."

\section{Enki ve Ninmah Miti}

Tanr1 Enki Mezopotamya mitolojisinde yeraltındaki tatlı suların tanrisı olarak bilinmekle beraber, ayn zamanda kurnazlığı, beceriyi ve yaratıcılı̆̆ da temsil eder. Ninmah ise onun eşi ve annesi Nammu'nun yardımcisıdır.

Enki ve Ninmah miti 114 satırıyla kısa sayılabilecek bir mitolojik hikâyedir. Bu metnin çevirisinin bir kısm1 S. N. Kramer tarafindan yayınlanmıştır (Kramer, 1944). Sonraki yıllarda bu hikâyeye ait yarım düzine kadar tablet parçaları C. A. Benito tarafindan incelenmiştir (Benito, 1969).

Metin, her şeyin ilk halini ve tanrıların çalışmak zorunda olduğunu ve bundan şikâyet ettiklerini belirten satırlarla başlar:
"O günlerde yukarısı aşağısı ayrimıştı, o gecelerde yukarısı ile aşağısı (birbirinden ayrildıklarnda) o yul (Tanrlarn) kaderleri tayin edildig̈inde Anunnalar dünyaya getirildiklerinde, Tannçalar evlendirildiklerinde, her biri kendi payna düseni aldığnda: Bazısı yukarıda, bazısı aşă̆zda döllendiklerinde ve anne olduklarnda, Tanrlarn yiyecek bulmalarn gerektiginde, hepsi çalısmaya koyuldu: Ikinci sirada olanlar angaryayla uğraștilar, kanal kazdular, toprak. yuğdular, dane ögüttüler: Ama ballerinden şikâyetçiydiler."

Sonraki satırlarda tanriların durumlarından fazlasıyla rahatsiz olmaları ve bunun sebebi olarak Enki'yi görmeleri ve Enki'nin annesi Nammu'nun tanriların bu şikâyetlerini oğluna aktarması yazılmaktadır. Bunun üzerine Enki insanları yaratır:

“Annesi Nammu'nun sözleri üzerine Enki yatağnndan çlktı......zeki, bilge, iyi düşünen,..., becerikli, biçimlendiren ber seyi, bir ana kahp imal etti. Yanı bassna koyup özenle inceledi ve doğası imal etmek olan Enki, tasarry bir anda kesinleștirince annesi Nammu'ya şölle dedi: 'Anne, düşündügün yaratık işte bazır tanrlarn yerine çalısmaya'.

Sen Apsu kizylarnndan bir parça kil alp yoğurduğunda bu ana kahbon kiline biçim verilecek ve sen kendin biçimlendirmek. istediğ̈inde doğasın, Ninmah eşlik edecek sana.......böylece onun kaderine bükmedeceksin ey annem ve Ninmah tanrlar için çalısmakla yükümlü kılacak onu?’

Mitin bundan sonraki bölümünde Enki'nin insanı yaratma başarısını kutlamak için şenlik düzenlenmesi, Ninmah'ın Enki'ye meydan okuması ve Enki'nin Ninmah'ın yarattığ altı kusurlu insanın kaderini düzelttiği ve son olarak yaratılan yedinci bir insan ile ilgili satırlar yer almaktadır.

Enki ve Ninmah mitinde öncelikle evrenin ve sonradan da insanın yaratılması konusu aktarılmıştır. Mezopotamya mitolojisinde kurnaz ve becerikli sifatlarıyla anilan Enki, insanı yaratma becerisinden dolayı tanrılar tarafindan takdir edilir ve şerefine bir ziyafet verilir. Yiyeceğin ve içeceğin bol tüketildiği bu eğlence sırasında Enki'nin eşi, Tanrıça Nammu'nun yardımcisı olan Ninmah Enki'ye meydan okur ve onun yarattığı iyi, mükemmel insana karşıllk kusurlu örnekler imal etmeyi önerir. Bu sayede, eksikliklerinden dolay1 tanrilara istenildiği gibi hizmet edemeyecek olan bu insanlara Enki'nin bir kader tayin edip edemeyeceğini görebilecektir.

Ninmah tarafindan altı insan yaratılır. Bunlar sırasıyla, elleri tutmayan, gözleri görmeyen, bacakları tutmayan, spermini tutamayan (erken boşalan) bir erkek, hamile kalamayan bir kadın ve doğuştan cinsiyetsiz insanlardır.

${ }^{2}$ Sumercesi AB.ZU, yeraltındaki tatlı su denizi. 
Enki, elleri tutmayanı kralın hizmetine vererek; gözleri görmeyene şarkı söyleme (ozanlık) yeteneği bahşederek; bacakları tutmayana doğaüstü bir yetenek vererek; erken boşalan kişiyi kötü ruh kovma ayiniyle kendi tarzında tedavi ederek; kısır kadını serbest aşka tahsis ederek; cinsiyetiz olanı da yine kralın hizmetine vererek kaderlerini tâyin eder. Son olarak Enki tarafindan yedinci bir insan yaratılır. Sumercesi $u_{4}$ $m u-u l$ olan bu insan türünün nasıl bir özellik taşıdığ1 tartışmalıdır. "Günüm uzakta" anlamına gelen kelime "(öleceğim) gün uzakta" olarak tercüme edilirse yeni doğmuş bir bebeği; “(doğduğum) gün uzakta” şeklinde tercüme edilirse de yaşlı bir insanı nitelemektedir. Bu varlığın fiziği kusurludur, gücü kuvveti yoktur, kendi kendini besleyemez hatta kendi başına ayakta duramaz. Kendi başına hiçbir ihtiyacını karşılayamadığı için hep başkalarına bağlıdır ${ }^{3}$. Ninmah bu yaratığa hiç bir kader tayin edemez ve umuldan hiçbir fayda sağlayamaz. Böylece Enki Ninmah'a, bir daha kendisine böyle bir meydan okumada bulunmamasını söyler.

Enki ve Ninmah miti Enki'nin becerisini, ustalığını yücelten bir hikâyeyi içermektedir. Metnin, Enki'nin kusurlu insanların kaderlerini tayin ettiği kısmı, onun her şeyi biçimlendirebilme ve sorunlan çözebilme yeteneğine vurgu yapmaktadır.

\section{Atrahasis / Yüce Bilgi Şiiri}

Akadca atrum "çok" ve bāsìsu "bilge" kelimelerinden oluşan Atrahasis -Atram-hasis olarak da yaz1lır- "Yüce Bilge" anlamina gelmektedir. Bu şiirin en eski versiyonu, Kasap-Aya tarafindan, Eski Babil'in büyük kralı Hammurabi'den sonra tahta çıkan dördüncü kral olan Ammi-saduqa'nın (M.Ö. 1646-1626) saltanat yıllarında yazılmıştır. Bu eser Sumerce'den çeviri olmayıp, tamamıla Eski Babil dönemi özellikleri taşıyan orijinal bir metindir.

Gılgameş destanında Tufan bahsinin geçtiği XI. tableti keşfedip yayınlayan George Smith tarafindan küçük bir parçası tespit edilen Yüce Bilge Şiiri'nin, sonraki ylllarda Danimarkalı Asurolog Laessoe'nun diğer parçaları bulup bunları düzenlemesiyle, bir yaratılış hikâyesi içerdiği anlaşılmıştır. Daha sonra W. G. Lambert tüm parçaları ve Kasap-Aya tarafindan yazılan bilinen en iyi korunmuş metni bir bütün olarak yayınlamıştır (Lambert ve Millard, 1965, No. 1-15). 1245 satırdan oluşan bu şiirle ilgili en ayrıntılı çalışma ise W. G. Lambert ve A. R. Millard tarafindan yapılmıştır (Lambert ve Millard, 1999).

\footnotetext{
3 Šumma İzbu serisinde farklı anomaliliklerle dünyaya gelen insanlardan, ölü doğan çocuklardan, cücelerden, yarım insanlardan ve insan görünüşüne sahip yaratıklardan da söz edilmektedir (Leichty, 1970, s. 36 vd.).
}

Atrahasis-Yüce Bilge metninin ilk bölümünde insanınyaratılışındanöncekizamandanbahsedilmektedir. $\mathrm{Bu}$ dönemde Anunnaku olarak anılan büyük tanrılar bütün angaryayı alt sinıftan tanrilar olan İgigu'lara yüklemişlerdi. İgigu'lar görevleri gereğince uzun yıllar boyunca toprağı kazıp suyu çıkardılar, kanallar açtılar ve daha sonra tükenip büyük tanrılara isyan ettiler. Bunun üzerine baş tannı Enlil yardımcısı Nuska'ya İgugularla uzlaşma görevi vermiştir. Sonunda tanr1 Ea bu durumdan kurtulmak için bir plan önermiştir:

"Ea ăğıı açtı. Kardeşlerine tanrlara seslendi: Neden suclayalım ki onlar, çalısmanm sonu yoktu, angarya da çok ağırdı! Her gün.... Yardım çı̆glklar pek ağırd. Ama bunun bir çaresi var. Belet-ili, Rahim burada olduğuna göre insan prototipini imal etsin. Tanrlarn boyunduruğunu o tassyacak, İgugularm boyunduruğunu o taşyacak, onlarn çalısmasim insan yüklenecek." "'

Ea'nın önerisi sonucunda insanlar yaratılmaya karar verilmiştir. Bu konuda Enki görevlendirilmiştir. Enki bu konudaki projesini anlatır:

"Enki ağz?m açt ve büyüle tanmlara seslendi: Her aym birinci, yedinci ya ada on beşinci günü banyo alp armma kararm çıkartacağım. O zaman kurban edilecek bir tanr. Suya girip arnmadan önce tanrlar, onun etine ve kanina Nintu kili katacak. Böylece tanr ve insan bir araya gelecek, birlesecek kilde. Böylece biz de dilediğimizi yapabileceğir tanrmin eti sayesinde. Insanda bir de rub olacak. Ölümünden sonra onun delili olacak bu bep canl kalarak. Bu rub orada olacak hep o unutulmasin diye!' ve büyük. Anunnaku'lar, kaderleri tâyin edenler hepsi beraber 'Evet' diye cevap verdiler."

Metnin sonraki satırlarında Enki'nin bu projesine göre insan prototipi gerçekleştirilmesi yazılmıştır:

"Ayn birinci, yedinci ya ada on beşinci günü Enki banyo alp arnma kararm çkartt. Ruh sabibi olan Tanr We meclisin ortasinda kurban edildi. Etine ve kanma Nintu kil katt. Tanr ve insan bir araya gelsin diye kilde birlestiler. Böylece tanrlar dilediklerini yapabildiler. Tanrmm eti sayesinde insanda bir de rub oldu. Ölümünden sonra onun delili olacak hep canle kalarak. Bu rub orada oldu o biç unutulmasin diye! Enki bu kili karar karmaz. Anunnaku'lar, büyük tanrlar çăğrd. İgigular da (şăgrrdi). Gelip tükürdüler kile. Sonra Mammi ağzım açt ve şunlar söyledi büyüle tannlara: 'Bana verdiğiniz işi tamamladim. Bu tanryy rubuyla birlikte kurban ettiniz: Ben de siz̨leri surtmı daki ağır angaryalardan kurtardım." "' 


\section{Sonuç}

Çivi yazılı kaynaklardaki, insanın yaratılışı ile ilgili mitolojik hikâyelere baktığımızda dikkat çeken bazı ayrıntılar görüyoruz. İnsan tamamen tanrılara yüklenen ağır işleri yâni angaryaları yüklenmesi için yaratılmıştır. Bu işleri yapmakla yükümlü daha alt sınıftan tanrilar olan İgigu'lar isyan etmişler ve artık bu işleri yapmayacaklarını belirtmişleridir. Bunun üzerine büyük tanrılar becerisiyle meşhur bir tanrı olan Enki'ye başvurmuşlardır. O da tanrıların ağır iş yükünü alacak olan insanı yaratmıştır. Enki bu işi yaparken bir kil topağını alıp yoğurmuş ve kurban edilen bir tanrının eti sayesinde insana bir ruh kazandırmıştır ve bu ruhun insan öldükten sonra da canlı kalacağına vurgu yapılmıştır.

\section{Kaynakça}

Benito, C. A. (1969). 'Enki and Ninmah' and 'Enki and the World Order'. Yayımlanmamış doktora tezi. University of Pennsylvania, Pennsylvania.

Bonnefoy, Y. (2000). Mitolojiler Sö̋lügü̆, 2 Cilt (L. Yılmaz, çev.). Dost Kitabevi Yayınları.

Bottéro, J. (2003). Mezopotamya: Yaž, Akıl ve Tanrlar (M. E. Özcan ve A. Er, çev.). Dost Kitabevi Yayınları.

Bottéro, J., ve Kramer, S. N. (2017). Meropotamya Mitolojisi (A. Tümertekin, çev.). Türkiye İş Bankası Kültür Yayınları.

Günbattı, C. (2017). Kültepe-Kaniss: Anadolu'da İlk Yazr, İlk Belgeler (İkinci Baskı). Kayseri Büyükşehir Belediyesi Kültür Yayınları.

Kramer, S. N. (1944). Sumerian Mythology: A Study of Spiritual and Literary Achievement in the Third Millenium B. C. American Philosophical Society.

Lambert, W. G., ve Millard, A. R. (1965). Cuneiform Texts from Babylonian Tablets in the British Museum, Part XLVI, Babylonian Literary Texts. The Trustees of the British Museum.

Lambert, W. G., ve Millard, A. R. (1999). Atra-Hasis: The Babylonian Story of the Flood. Eisenbrauns.

Leichty, E. (1970). The Omen Series Šumma İzu. Yale University Cuneiform Commentaries Project, Augustin.

Weidner, E. (1952/1953). Die Bibliothek Tiglatpilesers I. Archiv für Orientforschung, 16, 197-215.

\section{(c) $(1)(9)$ \\ 2020. Telif hakları yazar(lar)a aittir.}

Bu makale Creative Commons Atıf-GayriTicari 4.0 Uluslararası (CC BY-NC 4.0) lisansının hüküm ve şartları altında yayımlanan açık erişimli bir makaledir. 